\title{
Self-Respect and the DisRespect OF OTHERS
}

\author{
CHRISTINE BRATU \\ Ludwig-Maximilians-Universität Munich
}

\begin{abstract}
This paper addresses the question whether there is a rational connection between self-respect and the disrespect of others by engaging with the so-called Stoic View (SV) presented by Colin Bird. According to SV, there is no such connection because the disrespect other people show us can never provide us with a reason to lose our self-respect. This essay argues that SV is correct only from a third-personal perspective and false from a first-personal one. Since we are social cognizers, we use how other people treat us as evidence, for instance, about our moral status, and we are justified in doing so if we have no reason to dismiss them as untrustworthy. Distinguishing between the first- and third-personal perspectives is important to avoid victim-blaming. I show this by discussing an example from literature in which the protagonist concludes that she does not have equal moral status and thus lacks in self-respect without any mistake in her reasoning simply because she has been given false information about her moral status.
\end{abstract}

\section{Introduction}

In this paper, I address the question whether there is a rational connection between self-respect and the disrespect of others or, put differently, whether the disrespect other people show us ever provides us with a reason to lack or lose our self-respect. I do so by engaging with a position that Colin Bird puts forward in his paper "Self-Respect and the Respect of Others" and that he calls the Stoic View. On this view, the disrespectful behavior of other people never provides us with a reason to forfeit our self-respect. Bird concedes that sometimes it might be hard or even impossible for us to disregard the disrespectful behavior of others. We may thus be forgiven if the way we are treated affects our self-respect. But for Bird, this is merely a concession to the non-ideal state of the world. On an

Contact: Christine Bratu <christine.bratu@gmail.com> 
ideally rational level nothing speaks in favor of being affected in such a way. On Bird's Stoic View, then, there is no rational connection between self-respect and the disrespect of others.

In what follows, I argue that Bird's position provides only half the answer to our question. As I will show, there are two ways to interpret the Stoic View, and while on one interpretation, the Stoic View is correct, on the other, it is false. This allows me to conclude that while the disrespect of other people indeed never provides us with a reason to lack or lose our self-respect from a third-personal perspective, it can do so from a first-personal perspective.

My argument proceeds in three stages. In Section 2, I clarify how Bird understands the concepts of (having and losing one's) self-respect, disrespect, and providing a reason, and I reconstruct his argument for the Stoic View. In Section 3, I introduce the two ways the Stoic View can be interpreted and argue that it holds true only on one of them, namely a third-personal interpretation. I illustrate this point with an example taken from Tony Morrison's novel Home. In Section 4, I point out that while it has important emancipatory potential, adopting a thirdpersonal perspective on the connection between self-respect and disrespect also runs the risk of victim blaming. To avoid this risk, we must adopt a first-personal perspective as well. Section 5 concludes.

Before I begin, a final word of clarification. Bird develops the Stoic View by discussing the work of Avishai Margalit (see Bird 2010: 17), and his whole paper might be read as an essay on Margalit rather than as an exposition of his own philosophical theses. Since toward the end of his paper, however, Bird confesses to "a personal affinity" (Bird 2010: 34) for the Stoic View, I assume that Bird does not merely discuss the Stoic View as one possible position regarding the connection between disrespect and self-respect but that he actually endorses it.

\section{Bird's Stoic View}

My aim in this section is to reconstruct Bird's position and the argument with which he supports it. What Bird calls the Stoic View (SV), as noted, attempts to answer the question whether the disrespectful behavior of others ever provides a reason for an agent to lack or lose her self-respect (see Bird 2010: 19). Put differently, SV examines whether there is a rational connection between an agent's self-respect and the disrespect of others. Bird readily admits that we might also be interested in whether other types of connection obtain, for instance whether the disrespect of others causes those who are exposed to it to lack or lose their self-respect. ${ }^{1}$

1. In my view, there are three ways in which self-respect and the disrespect of others can be connected. I have already mentioned the rational connection, according to which B's disrespect is a reason for A to lack or lose her self-respect, and the causal one, according to which B's disrespect 
But since the investigation of causal connections falls within the purview of the empirical sciences (of social psychology or sociology, for instance), not of philosophy, Bird does not take a stand on this question. Instead, his SV claims the following:

$\left(\mathrm{SV}_{1 \text { st attempt }}\right)$ : B's disrespect toward $\mathrm{A}$ never provides a reason for $\mathrm{A}$ to lack or lose her self-respect.

Before I discuss Bird's defense of SV, it is necessary to clarify what Bird means by (i) "providing a reason," (ii) "self-respect," (iii) "lacking or losing self-respect," and (iv) "disrespect."

Let's start with (i) "providing a reason." Here the question arises: does SV claim that B's disrespect never provides A with a prima facie reason or that it never provides A with a conclusive reason to lack or lose her self-respect? In order to make SV as plausible as possible, I propose that we understand SV as a claim about prima facie reasons. Most people will concede from the start that B's disrespect does not provide $\mathrm{A}$ with a conclusive reason to lack or lose her self-respect since assuming so would leave A's self-respect too dependent on and vulnerable to the stance B takes toward her.

What does SV mean by (ii) "self-respect"? According to Bird (2010: 20), we commonly distinguish between (at least) two different kinds of self-respect, namely standards-self-respect and entitlement-self-respect. ${ }^{2}$ Bird goes on to focus entirely on entitlement-self-respect (entitlement-SR), which centers on the idea that we can take ourselves seriously or fail to do so by doing justice to our own moral status. According to Bird,

causes A to lack or lose her self-respect via some psychological process (this position can be found, for instance, in Thomas 1995: 264 and Dillon 1997: 244). Authors like Axel Honneth (1995: 129) or Heikki Ikäheimo (2009: 32-34) claim that there could also be a constitutive connection between disrespect and self-respect, such that B's disrespect conceptually entails that A lacks or loses her self-respect. Such a constitutive connection can only obtain if A's self-respect consists in (inter alia) being respected by other people (similar to how, for instance, A's being a star consists in A being admired by B). As will become clear later in this section, Bird believes that A's self-respect consists in a belief $A$ has about herself as well as in A's disposition to behave in a certain way. Thereforebecause A's self-respect is not made up of B's reactions at all-no such constitutive connection can obtain on Bird's account of self-respect. Michele Moody-Adams (1995: 276-285), too, speaks about the "Social Construction of Self-Respect" but with regard to what Bird calls standards-self-respect, which is a kind of self-respect I cannot discuss here.

2. In his distinction between different kinds of self-respect, Bird follows both Robin Dillon (1992; 2001) and Thomas Hill (1995a; 1995b). This distinction also mirrors the one between recognition and appraisal respect famously introduced by Stephen Darwall (1995: 183-184). I thank an anonymous reviewer for pointing this out to me. 
[e]ntitlement-SR involves a "confident conviction" that one has reckonable worth and associated entitlements that others are responsible for upholding. Those with entitlement-SR stand up for themselves and protest abuses without hesitation. They are aware of the treatment to which they are entitled from others and are prepared to insist upon getting it without shame and embarrassment. (Bird 2010: 20)

Put in more formal terms, person A has entitlement-SR if and only if (I) A believes that she has a specific set of moral entitlements and (2) A has the disposition to protest infringements of these entitlements. Entitlement-SR thus has a cognitive component (as A has to believe that she has a specific set of moral entitlements) and a behavioral one (as A has to protest if anyone infringes upon these entitlements). ${ }^{3}$ The precise form of these components varies depending on the general moral theory A subscribes to because different moral theories have different things to say about both the content and the grounding of moral entitlements. While Bird does not specify the content of the set of moral entitlements he assumes, he does elaborate on their grounding. According to the conception of entitlement-SR he relies on for SV, human beings have a specific set of moral entitlements in virtue of being "full members in the 'Family of Man"' (Bird 2010: 24), because they

exemplify a distinctive, iterated, configuration of genetic material not essentially different from that making up all of nature, capable of agency, self-consciousness, pain and pleasure, joy and sorrow, but with sharply limited control over the events that affect their lives. (Bird 2010: 34$)^{4}$

Given this understanding of self-respect, there are three different ways for person A (iii) to lack or to lose her self-respect (where "to lose one's self-respect" is

3. In positing both a cognitive and a behavioral component, Bird's notion of self-respect encompasses elements many in the debate consider necessary (for example Hill 1995a or Dillon 1992 and 2001). Dillon claims that these two components do not suffice because she thinks of selfrespect as a more complex phenomenon that "involves all those aspects of cognition, valuation, affect, expectation, motivation, action, and reaction that compose a mode of being in the world at the heart of which is an appreciation of oneself as having morally significant worth" (Dillon 2018). Hill's definition also comprises an additional element, as for him, A has (1) to believe that she has a specific set of moral entitlements and (2) to be disposed to protest against infringements of these entitlements as long as this protest does not become too costly for her (see Hill 1995a: 84). Nevertheless, as noted, neither Dillon nor Hill would question that the components Bird posits are necessary elements for a sensible notion of self-respect.

4. Bird does not elaborate on why having certain biological properties should entail moral status, which he would have to do if he sought to propose a comprehensive theory of self-respect. But as his aim is only to discuss the connection of (dis)respect and self-respect, he can leave this question unaddressed. 
to be understood as "to now lack the self-respect one once had"): A can either fail to believe that she has a specific set of moral entitlements or A can lack the disposition to protest infringements of these entitlements or both. While all three are cases in which A falls short of having entitlement-SR, Bird is only interested in cases of the first kind. According to Bird, those who lack entitlement-SR are people whose "otherwise perfectly clear recognition of general social expectations that individuals be treated with respect falters when they confront their own mistreatment at others' hands. 'Oh, it's nothing,' they may say, or: 'it's not worth bothering about"' (Bird 2010: 23). People who lack entitlement-SR "question whether they have the same worth as their fellow humans" and are in "inner doubt . . . about whether they in some way deserve their mistreatment." Thus, they do not "confidently and wholeheartedly view themselves as entitled to the very same respect they naturally extend to others" (Bird 2010: 23-24, emphases added). When SV makes use of the notion of lack or loss of self-respect, therefore, it refers to people who call into question whether they have a certain set of moral entitlements. ${ }^{5}$

The last notion to be clarified is (iv) disrespect, which Bird, unfortunately, does not elaborate. For the purposes of this paper, I would like to suggest the following minimal definition of disrespect: $B$ treats another person A disrespectfully if and only if B denies A's moral status, that is, if B denies that A has a specific set of moral entitlements. This understanding is modelled on Immanuel Kant's reasoning in the Metaphysics of Morals. There Kant claims that the vices that "violate the duties of respect for other men," that is, the vices of disrespect, are arrogance, defamation and ridicule (Kant 1996: 6:465-468). They consist in actions that call into question whether those at whom they aim have equal moral status.

Let's take stock. I originally introduced SV as follows: B's disrespect toward A never provides a reason for A to lack or to lose her self-respect. After clarifying the concepts SV uses, I can now spell it out in more detail:

(SV): B's disrespect toward A, that is, B's denial of (some or all of) A's moral entitlements, never provides a prima facie reason for A to call into question that she has a specific set of moral entitlements.

5. It is debatable whether this way of losing one's self-respect-i.e., by not displaying the cognitive component-is the most common or important kind. For instance, many people might suffer a loss of self-respect by not displaying the behavioral component, i.e., by not being disposed to protest against an infringement on their entitlements. Bird does not explain why he focuses only on the first way. I would speculate that he does so because, intuitively, it is more severe: a person who still knows what she is owed but is too shy or too afraid to stand up for it somehow seems better off than a person who has no or a false conception of what she is due. I thank an anonymous reviewer for pointing this out to me. 
This understanding of SV established, we can now examine how Bird argues for it. In a first step he says that we have a specific set of moral entitlements because we "exemplify a distinctive, iterated, configuration of genetic material" (Bird 2010: 34). Put differently, according to SV, we are owed special consideration simply in virtue of being human. There is nothing we have to do to deserve our set of moral entitlements. If we keep this in mind, Bird argues in a second step, it is hard to imagine how we might ever have "any sort of anxiety about whether we might be somehow 'unworthy' of our humanity. We are what we are" (Bird 2010: 34). Once we understand in virtue of which property we have our specific set of moral entitlements, we "no longer make the mistake of entangling our sense of self-respect with anxiety about the acceptance of others" (Bird 2010: 34). Bird's remarks may be organized into the following argument for $S V$ :

(1) To lack or lose her entitlement-SR, A has to call into question whether she has a specific set of moral entitlements.

(2) A has a prima facie reason to call into question whether she has a specific set of moral entitlements if and only if A lacks or loses the property in virtue of which she has these entitlements.

(3) According to SV, A has a specific set of moral entitlements in virtue of being human.

(4) Whether A has the property of being human is independent of her being treated disrespectfully by $\mathrm{B}$.

(5) Therefore, the property in virtue of which A has a specific set of moral entitlements is independent of A being treated disrespectfully by B.

(6) Therefore, B's disrespect never gives A a prima facie reason to call into question whether she has a specific set of moral entitlements.

(7) C. Therefore, B's disrespect never gives A a prima facie reason to lack or lose her entitlement-SR.

(1) is a conceptual claim that only states how SV understands the notion of lacking or losing one's self-respect. As I noted above, to lack or lose her self-respect A has to call into question whether she has a specific set of moral entitlements. (2) is an assumption Bird makes, but the following rationale shows that this assumption is on to something. Let's call A's belief that she has a specific set of moral entitlements $p$. The fact that $A$ has some property in virtue of which she has a specific set of moral entitlements makes A's belief that $p$ true. If A lacks or loses this property, the fact that made A's belief that $p$ true does not obtain (any longer). But that the fact that made $\mathrm{A}^{\prime} \mathrm{s}$ belief that $\mathrm{p}$ true does not obtain (any longer) certainly provides a reason for A not to believe that $\mathrm{p}$ (any longer). (3) is, again, a conceptual claim that spells out SV's understanding of the notion of 
entitlement-SR. (4) follows from this understanding of entitlement-SR because whether a being is human or not does not depend on how anybody treats her. (5) follows from (4) and (3), (6) follows from (5) and (2) and finally, the conclusion (C) - which is equivalent to SV-follows from (6) and (1). I therefore conclude that Bird's argument for SV is valid. The argument can be summed up as follows: Bird assumes that A only has a prima facie reason to call into question whether she has a specific set of moral entitlements if A lacks or loses the property in virtue of which she has these entitlements and, consequently, if A lacks or loses some or all of these entitlements. Given this assumption, B's disrespect can provide a prima facie reason for A to lack or lose her entitlement-SR only if B's disrespect somehow detracts from or diminishes A's moral entitlements. Bird then goes on to show that B's disrespect can never detract from these entitlements because the property in virtue of which A has her set of moral entitlements is not affected by B's behavior, be it disrespectful or otherwise. Bird therefore concludes that B's disrespect can never provide A with a reason to lack or lose her entitlement-SR.

\section{Two Ways to Interpret SV}

Having clarified SV and Bird's argument for it, let's now turn to what is problematic about this position. In this section, I will show that SV's key premise can be interpreted in two different ways and that SV holds true only on the first interpretation.

Using the structure presented above, the two most important premises in Bird's argument for SV are premises (2) and (4). According to (2), B's disrespect only provides a prima facie reason for A to call into question whether she has a specific set of moral entitlements if B's behavior is somehow entitlementdetracting. But according to (4), this can never be the case since the property in virtue of which A has moral entitlements is not affected by B's disrespect. In what follows, I do not take issue with (4), since it derives directly from Bird's understanding of entitlement-SR or, rather, from the moral theory he presupposes. Instead, I focus on (2).

(2) is a statement about which reasons agent A has to lack or lose her entitlement-SR, that is, reasons to call into question whether she has a specific set of moral entitlements. As such, it can be read from either from a third-personal perspective or a first-personal perspective. If we adopt a third-personal interpretation, (2) states which reasons A has given all reasons there are, that is, given full knowledge about all considerations that are pertinent to the issue of moral entitlements. In contrast, if we adopt a first-personal interpretation, (2) states which reasons A has given the reasons A has epistemic access to, that is, given the consider- 
ations A (explicitly or implicitly) knows to be pertinent to the issue of moral entitlements. ${ }^{6}$ Put differently, to understand (2) as a statement from a third-personal perspective means to assume an omniscient point of view and to ask, from that point of view, which considerations speak in favor of A calling her moral status into question. In contrast, to understand (2) as a statement from a first-personal perspective means to assume A's actual point of view and to ask which considerations speak in favor of A calling her moral status into question given all that A knows or fails to know about the world.

But while both interpretations of (2) are theoretically possible, only the thirdpersonal view renders (2) - and in consequence Bird's whole argument for SVtrue. To realize this, let's examine (2) from both perspectives, starting with the third-personal one. Let's assume that in assessing whether B's disrespect provides A with a prima facie reason to call into question whether she has a specific set of moral entitlements, we could draw on everything there is to know about moral entitlements (what they amount to, who has them and in virtue of what, etc.). In this epistemically privileged situation, it would be clear to us that A has a prima facie reason to call into question whether she has a specific set of moral entitlements only if she loses the property in virtue of which she has these entitlements in the first place-just as it would be clear to us that this can never happen because one's membership in the "Family of Man" cannot be revoked. In particular, we could easily dismiss B's disrespectful behavior as irrelevant to the question whether A has equal moral status or not because given our more informed perspective, we would know full well that $\mathrm{A}^{\prime}$ s moral status does not depend on how other people treat her. Thus, from the third-personal perspective, (2) is true.

If we assume the first-personal perspective, the result we arrive at depends on A's epistemic situation. For instance, if A is well educated about moral philosophy and knows what her moral entitlements hinge on, we would come to the same conclusion as in judging her situation from the third-personal perspective since A then just happens to know all that is relevant to the issue at hand. But what if $\mathrm{A}$ is in an epistemically less privileged position? Imagine, for instance, that A has no knowledge about the content and the grounding of her moral entitlements and that she is also fully aware of her ignorance regarding this issue. What if in such a situation, B-whom A in other contexts has come to know as knowledgeable and trustworthy - tells A that she does not have some of the moral entitlements other people do? Given her epistemically impoverished situ-

6. Thomas Scanlon puts the distinction between reasons there are and reasons a person has epistemic access to in terms of reasons for believing that $P$ and a person's operative reasons for believing that $P$ : "The first asks for an assessment of the grounds for taking P to be the case, while the second asks what, as a matter of biographical fact, Jones took to be a reason for believing it" (Scanlon 1998: 19). I thank an anonymous reviewer for this reference. 
ation, does B's disrespect constitute a prima facie reason for A to call into question her equal moral status?

Social epistemology says it does. Starting from the insight that human beings are social cognizers - since "virtually everything we know depends in some way or other on the testimony of others" (Lackey 2011: 71) - this branch of epistemology has developed criteria for the rational acceptability of testimony, criteria that determine the circumstances under which testimony has reason-giving force. For cases like the one at issue here, in which the testimony of one person is supposed to justify the moral belief of another (a belief, that is, about who has which set of moral entitlements), these criteria are especially stringent because it must be the case (a) that the testimony-receiver has no prima facie reason to call into question the credibility of the testimony-giver and (b) that the testimonyreceiver has a prima facie reason to call into question her own capacities of moral reasoning.7 The second scenario I have sketched above fulfills these conditions. On the one hand, A is aware of being uneducated about the issue of moral entitlements. With regard to this particular issue, she therefore has a prima facie reason to call into question her reasoning capacities - she just does not know enough about these matters to reason confidently about them. On the other hand, A has no prima facie reason to call into question B's credibility since she knows B to be otherwise knowledgeable and trustworthy and since, given her ignorance about her moral entitlements, she is not in a position to realize that B's statement about her moral status is false. Judging from the first-personal perspective of the agent, then, in cases such as the second scenario (in cases, that is, in which the agent is stuck in an epistemically impoverished situation, not knowing what her moral entitlements consist in and depend on) the disrespect of another person can provide her with a prima facie reason to call her moral entitlements into question and thus to lack or lose her self-respect. So if we understand premise (2) to be a statement about the reasons A has from her own first-personal perspective, it turns out to be false and so does, in consequence, SV.

To further illustrate this claim, consider the following example from Toni Morrison's novel Home. Morrison tells, among others, the story of Ycidra (known as Cee), a young African-American woman who lives in Georgia in the 1950s. Throughout her life, Cee is subjected to harmful and denigrating treatment. She is born while her family is on the run after a white lynch-mob has forced them to abandon their house and most of their possessions, which creates a trauma that deeply affects all of Cee's family members for years to come. In their new home

7. The criteria for the rational acceptability of moral testimony have to be this stringent because - as Alison Hills (2013: 552) puts it - when it comes to moral questions, it is particularly important to make up our own minds rather than to just do what others tell us to do. For a discussion of when it is rationally acceptable for us to rely on moral testimony, see Hills (2013: 553) and Jones (1999: 55). 
in the village of Lotus, Cee and her older brother Frank witness how a group of white men hides the body of an African-American man who has obviously been the victim of a violent crime in a field - an episode that leads Cee to believe that black lives do not matter much. This belief is buttressed by how her own grandmother, Lenore, treats her. The hardships she has had to endure have embittered Lenore, and she takes out her frustration on the most vulnerable member of her family, Cee. She often mistreats her granddaughter and calls Cee hopeless, a gutter-child that is unlovable and worthless. Lenore tells Cee that she is stupid, calling her "a fool" (Morrison 2012: 50) - a judgment Cee comes to agree with. Lenore's spite is a source of great suffering for Cee, since she (mistakenly) believes that "grandmothers, even when they've been hard on their own children, are forgiving and generous to the grandchildren" (Morrison 2012: 43). When she turns fourteen, Cee tries to escape Lenore's pernicious influence by running away, with a man who is taking advantage of her misery and inexperience. After her lover has stolen all her possessions and left her to fend for herself in Atlanta, Cee finds work in the house of Dr. Scott, where her ordeals continue when Scott starts performing experiments on her. Cee is on the verge of dying when she is rescued by her brother Frank who takes her back to Lotus. There, Cee is nursed back to health by a group of elderly African-American women. These women treat Cee with a mixture of tough love and care, restoring her bodily health while at the same time reprimanding her for letting Scott abuse her: "'You ain't a mule to be pulling some evil doctor's wagon.' 'You a privy or a woman?' 'Who told you you was trash?"' (Morrison 2012: 122). When she is almost cured, Miss Ethel, the most formidable of her caretakers, admonishes Cee one last time:

See what I mean? Look to yourself. You free. Nothing and nobody is obliged to save you but you. Seed your own land. You young and a woman and there's serious limitation in both, but you a person too. Don't let Lenore or some trifling boyfriend and certainly no devil doctor decide who you are. That's slavery. Somewhere inside you is that free person I'm talking about. Locate her and let her do some good in the world. (Morrison 2012: 125-126)

Miss Ethel's words lead Cee to reflect on how her life has gone so far. She comes to the following conclusion:

Anger wasn't available to her-she had been so stupid, so eager to please. As usual she blamed being dumb on her lack of schooling, but that excuse fell apart the second she thought about the skilled women who had cared for her, healed her. Some of them had to have Bible verses read to them because they could not decipher print themselves ... If not school- 
ing, then what? Branded early as a an unlovable, barely tolerated "gutter child" by Lenore, the only one whose opinion mattered to her parents, ... she had agreed with the label and believed herself worthless. Ida [Cee's mother] never said "You my child. I dote on you. You wasn't born in the gutter. You born into my arms. Come on over here and let me give you a hug." If not her mother, somebody somewhere should have said those words and meant them. (Morrison 2012: 128-129)

Cee's life story as narrated by Morrison lends itself as an example in discussing the connection between self-respect and the disrespect of others because it involves all the concepts introduced in Section 2. First, Cee is being treated disrespectfully by her grandmother Lenore. By calling her a "gutter child" and worthless, Lenore is denying Cee's moral status - a denial also manifest in Lenore's continual mistreatment of Cee. Second, Cee experiences a lack of entitlement-SR as she considers herself worthless. This lack of belief in her own worth plays an important part in the ordeal that ensues: Cee lets other people abuse her because she does not consider herself to deserve any better. Third, it is because of Lenore's disrespect toward her that Cee lacks entitlement-SR. For, as the last quote shows, it is because her own grandmother considers her unlovable that Cee accepts the label of worthlessness and questions whether she deserves to be treated differently.

How, then, should we assess Cee's situation? Does Lenore's disrespectful denial of her moral status give Cee a prima facie reason to call into question whether she has a specific set of moral entitlements, that is, whether the people who mistreat her are actually allowed to do so? From a third-personal perspective, it does not. As I explained above, to assess Cee's situation from a thirdpersonal perspective means to evaluate which reasons she has by drawing on all normative considerations relevant to the issue. And from this vantage point of full knowledge, Lenore's disrespectful behavior is easily recognized for what it really is: the result of a very unhappy life but in no way an indication of Cee's moral status because - at least on Bird's account-having full knowledge about the issue of moral entitlements entails knowing that they are grounded in our human nature and not in how our fellow human beings treat us. From a thirdpersonal perspective, then, Lenore's disrespect does not provide Cee with a prima facie reason to lack self-respect, just as Bird claims with SV.

The same does not hold true, however, if we adopt a first-personal perspective, that is, if we assess Cee's situation drawing only on those considerations to which she has epistemic access. Note, first, how epistemically impoverished Cee's situation is before she meets the other women in Lotus. Since her education has been insufficient and since, moreover, no one in her community has ever talked to her about such matters, Cee lacks all knowledge about the content and 
grounding of her moral entitlements. Cee fully realizes her ignorance, especially because her grandmother Lenore constantly reminds her of how stupid she allegedly is. Second, note that although Lenore treats her cruelly, Cee for a long time does not have a prima facie reason to mistrust her because she believes that grandmothers usually have their grandchildren's best interests at heart. Also, no one, not even Cee's own parents, calls Lenore out for abusing Cee. And finally, and perhaps most importantly, Lenore's denial of Cee's equal moral status fits well with how Cee's society treats African-Americans in general. For instance, the fact that white citizens are not prosecuted for violent crimes against AfricanAmerican citizens (wrongly) suggests that their moral status is somehow diminished. Thus Cee's situation fulfills the two criteria for the rational acceptability of moral testimony I introduced above: not only does Cee lack a prima facie reason to disregard Lenore's testimony as non-credible (thus fulfilling (a)), she also has a prima facie reason to be doubtful about her own capacity for moral reasoning (thus fulfilling (b)). Cee herself notes that if somebody had taken the trouble to tell her that she had the same moral entitlements as everybody else, she would have had a reason to mistrust Lenore and reject the sordid picture her grandmother painted of her. But since nobody did, on what grounds could she possibly have dismissed Lenore's denial of her equal moral status as misguided? If we adopt Cee's own perspective, then, we have to conclude that Lenore's disrespect does indeed provide her with a prima facie reason to lack entitlementSR. From this perspective, therefore, premise (2) of the argument for SV and in consequence SV are false.

\section{Why Distinguishing between the Two Interpretations is Important}

In the preceding section, I argued that there are two ways to interpret SV, either from a third-personal or from a first-personal perspective. Drawing on insights from social epistemology, which I illustrated with an example from Morrison's Home, I showed that while on the first interpretation SV is true, it is false on the second. Accordingly, while the disrespect of others never provides us with a prima facie reason to lack or lose our self-respect if we have full knowledge about our moral entitlements, it can give us a prima facie reason to call into question our equal moral status if we are in an epistemically impoverished situation and have never learned which moral entitlements we actually have. In this last section, I argue that we need to distinguish between the two perspectives because they are applicable in different circumstances.

In asking the question SV is meant to address-whether B's disrespect ever provides A with a prima facie reason to lack or lose her self-respect-we can 
have two different things in mind. (I) Either we want to assess whether $A$ is acting rationally, that is, whether in calling into question her equal moral status $\mathrm{A}$ is competently following the reasons she has access to (as opposed to making some mistake in weighing or discounting them). (II) Or we want to assess whether $A$ is getting it right, that is, whether in calling into question her equal moral status A's attitude toward herself is correctly tracking what is the case. Put differently, if we are interested in (I), we want to know whether A is competently using her faculties of moral reasoning, irrespective of whether, all things considered, the result of her reasoning is correct; the opposite is the case if we are interested in (II). Depending on whether we have (I) or (II) in mind, either the first-personal or the third-personal perspective described above is applicable. Answering (I) calls for adopting the first-personal perspective, since in this case we are interested in knowing whether A competently navigates the reasons to which she has access. In contrast, answering (II) calls for adopting the third-personal perspective, since in this case we are interested in knowing whether A gets it right, all things considered. If we confuse these perspectives, we simply misunderstand what (I) and (II) call for.

But not only do we misunderstand (I) and (II) when we confuse the firstpersonal and third-personal perspectives, we also run the risk of blaming the victim (if we mistakenly adopt the third-personal perspective) or of squandering emancipatory potential (if we mistakenly adopt the first-personal perspective). To illustrate this, let's return to the case of Cee. Imagine that in asking whether the disrespect Cee encounters gives her a prima facie reason to lack self-respect, we are interested in (I), that is, we seek to assess whether Cee in lacking self-respect acted rationally. Imagine also that by mistake we assume a third-personal perspective to answer this question. In this case, we would arrive at the conclusion that Cee acted irrationally since from an omniscient thirdpersonal perspective it is obvious that nothing ever speaks in favor of Cee losing faith in her equal moral status. But to conclude that Cee is irrational is clearly mistaken as Cee competently follows the reasons she has access to. Admittedly, Cee ends up with a wrong conception of her moral status, but this is not due to some incompetence on her part. Instead, Cee's social environment is to blame for providing her with false and insufficient information about her moral entitlements. Thus, if we mistakenly adopt a third-personal perspective when inquiring after Cee's rationality in lacking self-respect, we risk putting the blame for Cee's wrong conception of her moral status on Cee when it actually lies with her social environment.

Since Bird does not distinguish between the first-personal and third-personal perspective but seems to believe that the latter always applies, he accidently ends up engaging in such victim-blaming. According to him, even people like Cee, that is, people who have been provided with false or insufficient information 
about their moral status, act irrationally when they lack or lose their self-respect. All he concedes is "that circumstances can become so extreme that the irrational abdication of someone's self-respect is completely understandable, forgivable, and excusable" (Bird 2010: 37, emphasis added). In my view, this concession is insufficient: it is not only understandable that Cee questions her equal moral status, given the faulty information she has received it is rational for her to do so. By distinguishing between the first-personal and third-personal perspective and by adopting the former when assessing the rationality of people in situations like Cee's, we can avoid adding insult to injury.

So far, I have discussed the risk involved in adopting a third-personal perspective when in fact a first-personal one is called for. But mistakenly adopting a first-personal perspective also comes at a price. Imagine the opposite case: we want to know (II), that is, we want to know whether in calling into question her equal moral status Cee is getting it right. Imagine also that to assess this, we mistakenly adopt Cee's first-personal perspective. Given the false and insufficient information Cee possesses about her moral entitlements, we would have to conclude that Cee is correct in believing that she has diminished moral status. Understood as an answer to (II), an answer to the question whether all things considered Cee is correct in calling her equal moral status into question, this conclusion is not only false but also highly objectionable. Instead of empowering Cee's emancipatory struggle, convincing her that she deserves much more than she got, this conclusion would call for her acquiescing in the status quo. As socially engaged philosophers, we should avoid such squandering of emancipatory potential.

Let's sum up. In this section I have shown why it is important to distinguish between adopting a first-personal or a third-personal perspective when answering the question whether B's disrespect ever provides A with a prima facie reason to lack or lose her self-respect. As it stands, this question can be used to inquire after two different things: we can use it to ask either (I) whether A's reaction to B's disrespect was rational or (II) whether it was, all things considered, correct. To answer (I) we have to adopt A's first-personal perspective, to answer (II) we have to assume a third-personal perspective. Otherwise, we do not only misunderstand what (I) and (II) call for but risk arriving at conclusions that are ethically problematic, for responding to (I) from a third-personal perspective can amount to victim-blaming, while responding to (II) from a first-personal perspective can squander emancipatory potential.

This allows us, at long last, to come to a final assessment regarding Bird's SV. As I have shown in Section 3, Bird overlooks that there are two ways to interpret SV. Once we have established that SV can be read either from a first-personal (i.e., from A's) perspective or from an omniscient third-personal perspective, it becomes clear that Bird only gives us half the story. From the vantage point of 
full knowledge (in the Bird's eye view, as it were), it is true - just as Bird claimsthat $\mathrm{B}^{\prime}$ s disrespect never provides $\mathrm{A}$ with a reason to lack or lose her self-respect. But if A happens to be misinformed about her moral entitlements, the fact that other people deny her equal moral status can very well speak in favor of calling into question how she deserves to be treated.

\section{Conclusion}

In this paper, I have taken issue with the Stoic View (SV) according to which the disrespect of others never gives us a prima facie reason to lack or lose our self-respect. First, I showed that we need to distinguish between two interpretations of SV, since we can understand it as a claim about the prima facie reasons we have either from our first-personal perspective or from an omniscient thirdpersonal perspective. I then explained that human beings are social cognizers. As such, we treat what other people tell us as evidence for our actions and beliefs, and we are justified in doing so if we have no reason to dismiss their testimony as non-credible. As the example of Cee illustrated, there can be situations in which - at least from the first-personal perspective of the agent who is being treated disrespectfully - the disrespectful behavior of some people unfortunately serves as a credible statement about the agent's moral status. So contrary to what SV contends, there are situations in which-again, from the first-personal perspective of the agent affected-the disrespect of others provides the agent with a prima facie reason to call into question her equal moral status. I therefore proposed that we understand SV (such as Bird presents it) as only half the story about the rational connection between self-respect and the disrespect of others. Bird is correct to claim that what others say and do is irrelevant to how we should think about our moral entitlements from a third-personal perspective, but from a first-personal perspective it does not have to be so. I concluded by pointing out that it is important to distinguish between these two perspectives, especially in order to avoid victim-blaming: as the case of Cee also showed, people sometimes conclude that they lack some moral entitlements without making any mistake in their reasoning, simply because they have been given false or insufficient information about their moral status.

Critics could accept my argument but wonder how pertinent it really is. For how often do we encounter cases like Cee's in real life? That is, how often is it the case that people know as little about their moral status as Cee does, such that, for instance, they do not realize that the fact that somebody treats them disrespectfully in itself constitutes a prima facie reason to call their credibility into question? Under normal conditions, people know about the set of moral entitlements they have, either because their loved ones tell them about their moral status or 
because they learn about it in school or at church or through their society's public discourse or through art. ${ }^{8}$ Put differently, critics might accept that cases like Cee's show that in theory we should distinguish between a first-personal and a third-personal interpretation of SV, but they might nevertheless believe that in practice this distinction does not really matter.

Ultimately, it is an empirical question whether Cee's case constitutes a rare exception or not. As long as critics cannot produce credible numbers to sustain their doubt, both they and I should thus remain agnostic on this question. But at least to me, it seems that such critics' stance would be overly optimistic, especially when it comes to members of marginalized social groups. I do not thereby want to suggest in any way that marginalized people are necessarily ignorant about their equal moral status. But as long as we do not presuppose some sort of inner moral sense-which would always get it right and could not, moreover, be fooled by our social environment-we have to accept that at least in part we learn about morality and about our own moral status from what other people tell us and from how they treat us. History shows that for a very long time, members of some social groups did not have unrestricted access to unbiased information about their moral status. Admittedly, there have always been countercultures, groups of people who knew that they had equal moral status even if society in general told them otherwise (such as, for instance, the other women of Lotus in Morrison's novel). But again, it seems overly optimistic to assume that every member of every marginalized social group has been part of or in touch with a countercultural movement. People who find themselves in a situation like Cee's, people who have insufficient or false information about their moral status, might therefore be less rare than critics might suggest. To do justice to their complex lived experience, we need to distinguish the two interpretations of SV I put forward.

\section{Acknowledgments}

I thank Robin Dillon for many inspiring discussions on the topic of self-respect during my stay as a visiting researcher at Lehigh University. I also thank Sarah Akgül, Monika Betzler, Moritz Dittmeyer, Nadja El Kassar, Hilkje Hänel, Johanna Müller, Jonathan Seglow, Anna Wehofsits and two anonymous referees for helpful feedback on earlier drafts of this paper. Many thanks also to the participants of Jan-Christoph Heilinger's Colloquium at the Munich Center for Ethics, Lisa Herzog's Political Theory Colloquium at the Bavarian School of Public Poli-

8. Richard Rorty has famously argued that in liberal democracies it is, in fact, novelists who are best suited to educate us about morality (see Rorty 1989: 95 as well Chapters 7 and 8 there). 
cy, Jay Wallace's Einstein Ethics Group Colloquium, colloquia at the universities of Erlangen and Bielefeld as well as the panel on Epistemic Status and Respect at ECAP 9 in Munich for helping me improve this paper.

\section{References}

Bird, Collin (2010). Self-Respect and the Respect of Others. European Journal of Philosophy, 18(1), 17-40.

Darwall, Stephen (1995). Two Kinds of Respect. In Robin Dillon (Ed.), Dignity, Character, and Respect (181-197). Routledge.

Dillon, Robin (1992). How to Lose Your Self-Respect. American Philosophical Quarterly, 29(2), 125-139.

Dillon, Robin (Ed.) (1995). Dignity, Character, and Respect. Routledge.

Dillon, Robin (1997). Self-Respect: Moral, Emotional, Political. Ethics, 107(2), 226-249.

Dillon, Robin (2001). Self-Forgiveness and Self-Respect. Ethics, 112(2), 53-83.

Dillon, Robin (2018). Respect. In Edward Zalta (Ed.), The Stanford Encyclopedia of Philosophy (Spring 2018 ed.). Retrieved from https://plato.stanford.edu/archives/spr2018/ entries/respect/

Hill, Thomas E. (1995a). Servility and Self-Respect. In Robin Dillon (Ed.), Dignity, Character, and Respect (76-92). Routledge.

Hill, Thomas E. (1995b): Self-Respect Reconsidered. In Robin Dillon (Ed.), Dignity, Character, and Respect (117-124). Routledge.

Hills, Alison (2013). Moral Testimony. Philosophy Compass, 8(6), 552-559.

Honneth, Axel (1995). The Struggle for Recognition: The Moral Grammar of Social Conflicts. MIT Press.

Ikäheimo, Heikki (2009). A Vital Human Need: Recognition as Inclusion in Personhood. European Journal of Political Theory, 8(1), 31-45.

Jones, Karen (1999). Second-Hand Moral Knowledge. The Journal of Philosophy, 96(2), 5578.

Kant, Immanuel (1996). Practical Philosophy. Mary J. Gregor (Ed. and Trans.). Cambridge University Press.

Lackey, Jennifer (2011). Testimony: Acquiring Knowledge from Others. In Alvin Goldman and Dennis Whitcomb (Eds.), Social Epistemology: Essential Readings (71-91). Oxford University Press.

Moody-Adams, Michele (1995). Race, Class, and the Social Construction of Self-Respect. In Robin Dillon (Ed.), Dignity, Character, and Respect (271-289). Routledge.

Morrison, Toni (2012). Home. Vintage.

Thomas, Laurence (1995). Self-Respect: Theory and Practice. In Robin Dillon (Ed.), Dignity, Character, and Respect (251-270). Routledge.

Rorty, Richard (1989). Contingency, Irony, and Solidarity. Cambridge University Press.

Scanlon, Thomas (1998). What We Owe To Each Other. Belknap. 